\title{
Introduction
}

\section{Pacific Island heritage: An overview}

\author{
Jolie Liston ${ }^{1}$, Geoffrey Clark ${ }^{1}$ and Dwight Alexander ${ }^{2}$ \\ 1. Archaeology and Natural History, College of Asia and the Pacific, The Australian National University, Australia \\ 2. Bureau of Arts and Culture, Ministry of Community and Cultural Affairs, Republic of Palau
}

The conference Pacific Island archaeology in the 21st century: Relevance and engagement was held in the Republic of Palau from 1-3 July in 2009 and was attended by more than 300 local and international participants. The conference assessed how Pacific Islander culture is integral to preserving and protecting the natural and cultural resources of Oceania as both are currently threatened by rapid economic, social and environmental changes. The premier registrar of natural and cultural sites is the UNESCO World Heritage List, which currently consists of 911 properties, of which 77\% are cultural, 20\% natural and 3\% mixed. The tropical Pacific Islands have only a small number of listed properties, with many major islands and archipelagos underrepresented. At the national level, cultural properties are often outnumbered by natural parks and protected marine and forest environments. Many prehistoric sites in the Pacific are owned/ occupied by local groups with traditional land rights, who have the primary responsibility for managing historically significant sites, prehistoric as well as those of recent age. The focus of the conference was therefore on community engagement in cultural heritage preservation and management. Under rapid economic development, the social effects of globalisation and the nascent impacts of climate change, communities and governments in the Pacific Islands will need to protect their heritage by marshalling specialised resources at home and abroad and increasing community involvement in cultural and natural site preservation. Such an approach reinforces a necessary and productive union between natural and cultural resource management, which allows the views and expertise of community stakeholders to be combined appropriately with the knowledge of academics, scientists and heritage professionals.

The conference was held to facilitate and reinforce these delicate relationships while emphasising the need for groups involved in heritage management to deepen their understanding of each other's methods and perspectives. In the Pacific, for instance, oral history and many aspects of subsistence collection and social activity are culturally prescribed and sanctioned as 'traditional' by long use. In popular thought, and indeed in some public policy, the traditional behaviour of insular societies can be taken as the manifestation of unchanging cultures that are highly vulnerable to contemporary challenges such as climate change, high rates of migration 
and the societal impacts of globalisation. Yet archaeology and palaeoenvironmental studies demonstrate that not all cultural behaviour in Pacific societies was retained in the past to become 'traditional'. There is extensive evidence that Pacific societies have frequently adapted to a multitude of environmental and social events in the past. It is this historical evidence for continuity, resilience and resourcefulness that is evident today in many Pacific communities where engagement with cultural heritage is increasingly seen as a means of strengthening and retaining group identity and preserving the local environment while allowing many Pacific Islanders to participate effectively in an increasingly globalised economy and society.

As the papers in this volume demonstrate, knowledge of the past is continually used to adjust to cultural and natural changes, and physical sites of tangible heritage frequently act as a focus for community and national identity in a similar way to the performance of traditional chants, songs, oratory and dances. Preservation of archaeological and historic sites assists in the maintenance of community history, therefore, as sites function as a cultural mnemonic and community management of heritage sites often leads to renewed interest in traditional activities, increased local and international tourism, and increased social cohesion. In our view, Pacific societies that are grounded in their tangible and intangible cultural heritage are more likely to be cohesive and able to respond effectively to the environmental and social shifts forecast in the 21 st century.

As the first large-scale Pacific heritage meeting held in Micronesia, the conference provided an opportunity to build region-wide networks that could be used to foster sustainable growth and economic development around community management of cultural and natural heritage sites. The personal and professional networks created during the conference will assist in creating a critical mass of expert opinion and on-the-ground management skills that will benefit heritage sites in many Pacific Islands. The conference was organised around a series of concurrent symposia, panel discussions and public lectures, with a day devoted to heritage ecotourism. The sessions examined indigenous, public and scholarly interpretations of cultural sites, island environments and climate change, indigenous heritage research and management, the connections between oral tradition and archaeology, practical approaches to heritage tourism, community involvement in heritage management, the role of museums in developing nations, and strategies for combining natural and cultural resource management.

James Dion, Associate Director of the Centre for Sustainable Destinations, National Geographic Society, gave the keynote address and chaired a session on the use of communitybased heritage ecotourism to generate income through sustainable economic development. President of the World Archaeological Congress Professor Claire Smith (Flinders University) spoke on global trends in cultural heritage and how these will affect Pacific Island nations. Dr Rufino Mauricio, Chairman of ICOMOS Pacifica, Director of the FSM National Historic Preservation Office, and Secretary General of the FSM National Commission on UNESCO, gave a second keynote on the relevance of cultural and historical resources, with an example of the merging of oral history and archaeology in Pacific heritage management. An evening presentation was given by Professor Patrick Nunn, Professor of Oceanic Geoscience, University of the South Pacific, followed by a lengthy question and answer session about his presentation on the impact that changing sea levels will have on Pacific Island environments and societies.

More than 300 people attended the conference, with 90 off-island delegates and the remainder from Palauan communities. Represented were academic institutions, government agencies, heritage resource consultants, environmental groups, tourism associations, educators, chiefly councils, museums, NGOs, and construction and tour businesses. Delegates came from 18 nations, including Sweden, Germany, New Zealand, Australia, Fiji, Rapa Nui, the United 
States, Samoa, Vanuatu, New Caledonia, Guam, the Commonwealth of the Northern Marianas, the Federated States of Micronesia, the Republic of the Marshall Islands, French Polynesia and the Philippines.

The issues of greatest interest concerned contemporary economic development and climate change, particularly the effects of a rising sea level, the need to merge natural and cultural heritage management rather than treat each separately, and the implementation of community strategies to manage heritage sites. Heritage tourism was seen by many participants as a sustainable form of economic development that could be used by a community to conserve its heritage sites and employ local people. The presentation by the Guampedia Foundation on the use of its website to provide heritage resources was also enthusiastically received and several Pacific nations are now exploring the possibility of creating internet sites dedicated to their national and community heritage. In a peer-reviewed dictionary format, such sites will make information about the culture and traditions of a Pacific Island available to local students, islanders living outside the Pacific, and other interested parties.

The strong public participation by Palauan people through attendance and involvement in sessions was a conference highlight and bridged a long-standing divide between foreign researchers and local communities actively seeking information to manage heritage sites. Too often, the science of archaeology has been separated from the practical realities of site management, and although there are several cogent reasons for this division, there is a growing understanding that heritage sites throughout the Pacific are a fragile, limited and significant cultural resource that need urgent protection. Combining the archaeological 'science' from Pacific archaeological sites with the living connection and stewardship of the local community can make a strong and often compelling case for site protection and preservation at national and international levels. Division between foreign experts and local groups, often glossed as debate about 'who owns the past', has ignored the reality that important cultural sites are being degraded and destroyed at an unprecedented rate. If groups and individuals with a shared historical focus and respect for the past do not combine their resources, there will be far fewer heritage sites in the Pacific for future generations. 